\title{
Determination of snow-covered area in different land covers in central Alaska, U.S.A., from aircraft data - April 1995
}

\author{
Dorothy K. Hall, ${ }^{1}$ James L. Foster, ${ }^{1}$ Alfred T. C. Chang, ${ }^{1}$ Carl S. Benson, ${ }^{2}$ Janet Y. L. Chien ${ }^{3}$ \\ ${ }^{1}$ Hydrological Sciences Branch, Code 974, NASA/Goddard Space Flight Center, Greenbelt, MD 20771, U.S.A. \\ ${ }^{2}$ Geophysical Institute, University of Alaska, Fairbanks, AK 99775-7320, U.S.A. \\ ${ }^{3}$ General Sciences Corporation, 6100 Chevy Chase Drive, Laurel, MD 20707, L.S.A.
}

\begin{abstract}
During April 1995, a field and aircraft experiment was conducted in central Alaska in support of the Moderate Resolution Imaging Spectroradiometer (MODIS) snow-mapping project. The MODIS Airborne Simulator (MAS), a 50 channel spectroradiometer, was flown on board the NASA ER-2 aircraft. An objective of the mission was to determine the accuracy of mapping snow in different surface covers using an algorithm designed to map global snow cover after the launch of MODIS in 1998. The surface cover in this area of central Alaska is typically spruce, birch, aspen, mixed forest and muskeg. Integrated reflectance, $R_{\mathrm{i}}$, was calculated from the visible/near-infrared channels of the MAS sensor. The $R_{\mathrm{i}}$ was used to estimate different vegetation-cover densities because there is an inverse relationship between vegetation-cover density and albedo in snow-covered terrain. A vegetation-cover density map was constructed using MAS data acquired on 13 April 1995 over central Alaska. In the part of the scene that was mapped as having a vegetation-cover density of $<50 \%$, the snow-mapping algorithm mapped $96.41 \%$ snow cover. These areas are generally composed of muskeg and mixed forests and include frozen lakes. In the part of the scene that was estimated to have a vegetation-cover density of $\geq 50 \%$, the snow-mapping algorithm mapped $71.23 \%$ snow cover. These areas are generally composed of dense coniferous or deciduous forests. Overall, the accuracy of the snow-mapping algorithm is $>87.41 \%$ for a 13 April MAS scene with a variety of surface covers (coniferous and deciduous and mixed forests, muskeg, tundra and frozen lakes).
\end{abstract}

\section{INTRODUCTION}

One of the key problems in global snow-cover mapping is the measurement of snow cover in forested areas. In this paper, we address this problem by applying an algorithm to map snow cover using remotely sensed data in different land covers in Alaska. We also estimate vegetation-cover density and determine the accuracy of mapping snow in different surface covers. Previous work has addressed the relationship between albedo and forest-cover density using reflectances as a surrogate measurement of forest density (Robinson and Kukla, 1985; Foster and others, 1994). From 3 to 24 April 1995, a field and aircraft campaign was conducted in central and northern Alaska in support of the Earth Observing System (EOS) Moderate Resolution Imaging Spectroradiometer (MODIS) snow and ice global-mapping project. MODIS, a 36 channel instrument with a spatial resolution ranging from $250 \mathrm{~m}$ to $1 \mathrm{~km}$, will operate in the visible through the thermal-infrared parts of the electromagnetic spectrum and will be flown on the first EOS platform to be launched in 1998. The MODIS Airborne Simulator (MAS) is a 50 channel spectroradiometer that is flown on board the NASA ER-2 aircraft. MAS data are useful for simulating the MODIS data in terms of spectral coverage for refining the algorithm that has been developed to map global snow cover using MODIS data following its 1998 launch.

\section{BACKGROUND}

An algorithm has been developed to map daily, global snow cover using MODIS data at $500 \mathrm{~m}$ resolution (Hall and others, 1995). For MAS data, the prototype algorithm, which is still evolving, relies on the Normalized Difference Snow Index (NDSI) and a threshold test to identify snow:

$$
\text { NDSI }=\frac{(\text { MAS band } 1-\text { MAS band } 10)}{(\text { MAS band } 1+\text { MAS band } 10)}
$$

If the NDSI $\geq 0.4$ and the MAS band 7 reflectance is $>11 \%$, then a pixel is mapped as snow. The band 7 threshold test discriminates snow and water, because water may have NDSI values $\geq 0.4$ and thus be confused with snow. Other threshold tests, based on vegetation-canopy modeling, may be included in the future to map more snow cover in forested areas (Klein and others, 1997).

Using Landsat Thematic Mapper (TM) and MAS data, our snow-mapping algorithm has been shown to be very effective in mapping snow cover in alpine, tundra and prairie landscapes according to work in progress. Snow cover in tundra and prairie areas can be mapped with nearly $100 \%$ accuracy (unpublished data, 1997) and snow in alpine areas can be mapped with $95 \%$ accuracy when $50 \%$ or more of a pixel is snow-covered (Hall and others, 1995). However, in forested areas, some snow cover which is known to be pre- 
sent beneath the trees, is not mapped because the trees obscure the snow from view.

The MAS is a 50 channel spectroradiometer that acquires imagery in the wavelength range $0.527-14.35 \mu \mathrm{m}$ (Table 1). The MAS collects image data with a ground resolution of $50 \mathrm{~m}$ from $20000 \mathrm{~m}$ altitude and has a cross-track scan width of $85.92^{\circ}$ giving a total field of view of $37.25 \mathrm{~km}$ on the ground (King and others, 1996).

\section{Table 1. Spectral ranges of the MODIS Airborne Simulator (MAS) channels 1-9}

\begin{tabular}{cc}
\hline Channel & Spectral range \\
& \\
\hline 1 & $0.527-0.571$ \\
2 & $0.631-0.684$ \\
3 & $0.683-0.725$ \\
4 & $0.725-0.766$ \\
5 & $0.765-0.807$ \\
6 & $0.806-0.848$ \\
7 & $0.848-0.891$ \\
8 & $0.893-0.926$ \\
9 & $0.924-0.970$ \\
\hline
\end{tabular}

Crown closure, basal area the cross-sectional area of tree stems per unit ground area) and foliage biomass are all inversely related to visible reflectance and scene brightness of Landsat imagery (Franklin, 1986). As crown closure and basal area increase, reflectance decreases in the photosynthetic regions of the visible spectrum due to increased leaf area, absorption and shadowing within the canopy.

Robinson and Kukla (1985) used Defense Meteorological Satellite Program (DMSP) visible and near-infrared data to estimate maximum surface albedo over snow-covered terrain, using a linear interpolation between the brightest tundra and the darkest snow-covered forest. They assigned parameterized albedos of 0.18 for very dense coniferous forest and 0.80 for open tundra and open farmland. Foster and others (1994) found that the albedo data in forested regions was indicative of the actual fractional forest cover, and used the Robinson and Kukla (1985) reflectance measurements as a surrogate for assessing the percentage of forest cover in snow-covered terrain in the Northern Hemisphere. The normalized difference vegetation index (NDVI) is a fairly strong measure of vegetation biomass and has been found to have a close relationship with the photosynthetic capacity of specific vegetation types (Townshend and others, 1993). But biomass is not necessarily a useful indicator of fractional-forest-cover density, therefore Foster and others (1994) decided that albedo data were more useful for estimating forest cover than was NDVI. They employed a relationship derived from DMSP-derived albedos to map fractional forest cover. This was then used to correct the Chang and others (1987) algorithm that employs Scanning Multichannel Microwave Radiometer (SMMR) passive-microwave data to map snow cover and depth. Use of this technique to estimate fractional forest cover as a function of reflectance improved the estimates of continental snow mass.

Hall and others (1989) employed data from the Landsat TM sensor to calculate an integrated reflectance, $R_{\mathrm{i}}$, or a reflectance integrated over some or all of the reflective part of the electromagnetic spectrum. The TM-derived integrated reflectance values of glaciers in Alaska were shown https://doi.org/10.3189/1998AoG26-1-149-155 Published online by Cambridge University Press 150 to correspond well with field measurements and theoretical data. While $R_{\mathrm{i}}$ is not synomymous with albedo, it is a way of assigning a single reflectance value to a series of individual reflectances. This technique was also applied to the MAS data in the present study.

\section{STUDY AREA AND METEOROLOGICAL CONDI- TIONS DURING THE STUDY PERIOD}

Flights over areas containing a variety of land covers in central Alaska were conducted. In the vicinity of Fairbanks, Alaska, $\sim 65^{\circ} \mathrm{N}, 148^{\circ} \mathrm{W}$, a grid pattern was flown on $5,6,13$ and 21 April 1995 that covered an area from approximately $64-65^{\circ} \mathrm{N}$ and $145-150^{\circ} \mathrm{W}$. Within this "Fairbanks grid", at least the following land covers are encountered: sprucebirch forest, black-spruce forest, muskeg, water-sedge tundra, cotten-sedge tundra and dryas meadows, and barren areas (Kuchler, 1985). Ice- and snow-covered lakes are also present. On 21 April 1995 much of the area was covered by cirrus clouds.

Continuous snow cover was present over central and northern Alaska during most of the study period except in the downtown part of Fairbanks where much of the snow had already melted by 5 April. During the study period, the snow melted rapidly; average daily air temperatures varied from a low of $0^{\circ} \mathrm{C}$ to a high of $7^{\circ} \mathrm{C}$. Virtually no additional snow accumulated in central Alaska during the study period.

Table 2. Snow depth and water equivalent in Fairbanks and snow depths at Ester Dome on selected dates

\begin{tabular}{cccc}
\hline Date & \multicolumn{2}{c}{ Fairbanks } & Ester Dome \\
& $\begin{array}{c}\text { Depth } \\
\mathrm{cm}\end{array}$ & $\begin{array}{c}\text { Depth } \\
\mathrm{cm}\end{array}$ \\
& $\mathrm{cm}$ & \\
\hline $27 / 3 / 95$ & 68 & 13.9 & $*$ \\
$1 / 4 / 95$ & 59 & 15.1 & 100 \\
$2 / 4 / 95$ & 54 & 14.6 & $*$ \\
$6 / 4 / 95$ & 39 & 14.3 & $*$ \\
$7 / 4 / 95$ & 35 & 12.5 & 100 \\
$8 / 4 / 95$ & $*$ & $*$ & $*$ \\
$11 / 4 / 95$ & 23 & $\dagger$ & $*$ \\
$13 / 4 / 95$ & $\dagger$ & & $*$
\end{tabular}

* No measurements were taken on these days.

† Snow was essentially gone by $13 / 4 / 95$.

Table 2 shows snow depths from a location in Fairbanks (elevation $150 \mathrm{~m}$ ), and at Ester Dome (elevation $610 \mathrm{~m}$ ), which is about $5 \mathrm{~km}$ northwest of Fairbanks. The measurements at Ester Dome were obtained from a north-facing slope. In addition to snow depths, snow pits were dug, and other snow measurements (e.g. snow water equivalent and density profiles) were obtained as well as information on snow crystals (Foster and others, 1996). Figure 1 shows snow depth and density profiles from the location in Fairbanks. Note that the errors for the water equivalents in Figure 1 are $\pm 0.5 \mathrm{~cm}$.

A vegetation map of Alaska (Kuchler, 1985) was used to determine vegetation type. In addition, a 9 September 1994 Landsat TM scene was used to perform a general classification of the vegetation in a small area within the Fairbanks grid as defined on the MAS data. The preliminary classification was accomplished by combining TM bands 3,4 and 5 covering the spectral regions of $0.63-0.69,0.76-0.9$ and 1.55 
$1.75 \mu \mathrm{m}$, respectively. This permits the following categories of surface cover to emerge: coniferous, deciduous and muskeg (personal communication from D. Verbyla). A more detailed vegetation classification will be implemented at the University of Alaska but is not yet available.

The maximum and minimum visible/near-infrared integrated reflectances (MAS channels 1-9) (Table 1) were measured in a MAS sub-scene from a location near Harding Lake acquired on 13 April 1995. The energy distribution in the spectrum of direct solar radiation at different levels of the atmosphere is known for specified atmospheric conditions. By knowing the reflectance of a specified target (for example, the reflectance of snow, measured using the MAS sensor), at certain wavelengths, one can compute $R_{\mathrm{i}}$ using solar energy, $S E$, and measured reflectance, $R$, according to the following formula (Hall and others, 1989),

$$
R_{\mathrm{i}}=\left(\sum_{0.527}^{0.970} S E \times R\right) \div \sum_{0.527}^{0.970} S E
$$

where $S E$, in $\mathrm{Wcm}^{2}$, is found in Kondrat'ev

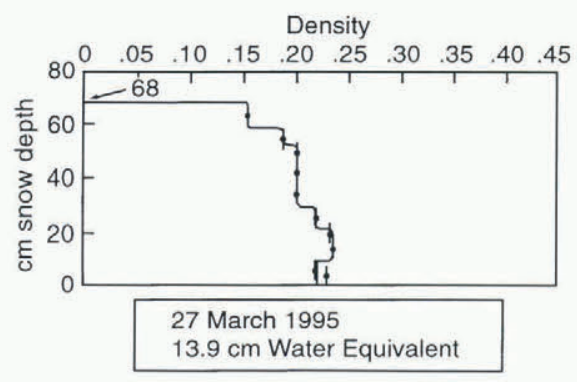

Density
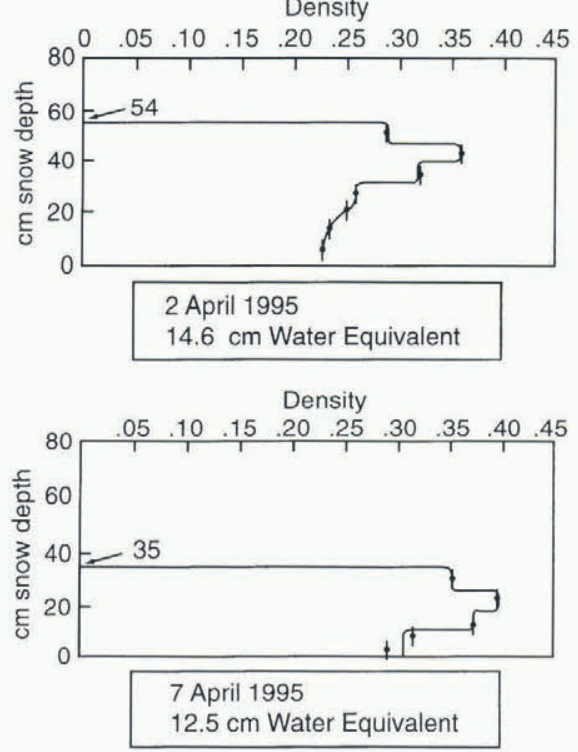

assuming a clear-sky atmosphere that contains $1.0 \mathrm{~cm}$ of precipitable water, $0.35 \mathrm{~cm}$ of ozone and an aerosol concentration of $200 \mathrm{~cm}^{-3}$ at the Earth's surface. Values are given for an atmospheric mass, $m=1.5$. The summation from 0.527 to $0.970 \mu \mathrm{m}$ represents the MAS channels $1-9$. Data from the visible and near-infrared part of the spectrum were also used by Robinson and Kukla (1985), Knap and Oerlemans (1996) and Nolin and Stroeve (1997) in order to map snow and ice albedo.

Vegetation-cover density was estimated from $R_{\mathrm{i}}$ values in the 13 April MAS scene in the following way. The highest $R_{\mathrm{i}}$ values correspond to snow-covered bare areas or areas covered with very low vegetation or snow-covered ice, and the lowest $R_{\mathrm{i}}$ values correspond to the densest forests. The linear relationship between $R_{\mathrm{i}}$ and vegetation-cover density is developed from the maximum and minimum reflectances in the scene, as has been done by other researchers, to estimate snow albedo and vegetation density. This relationship is then used to assess the ability of the snow-mapping algorithm to map snow in a variety of vegetation-cover densities.
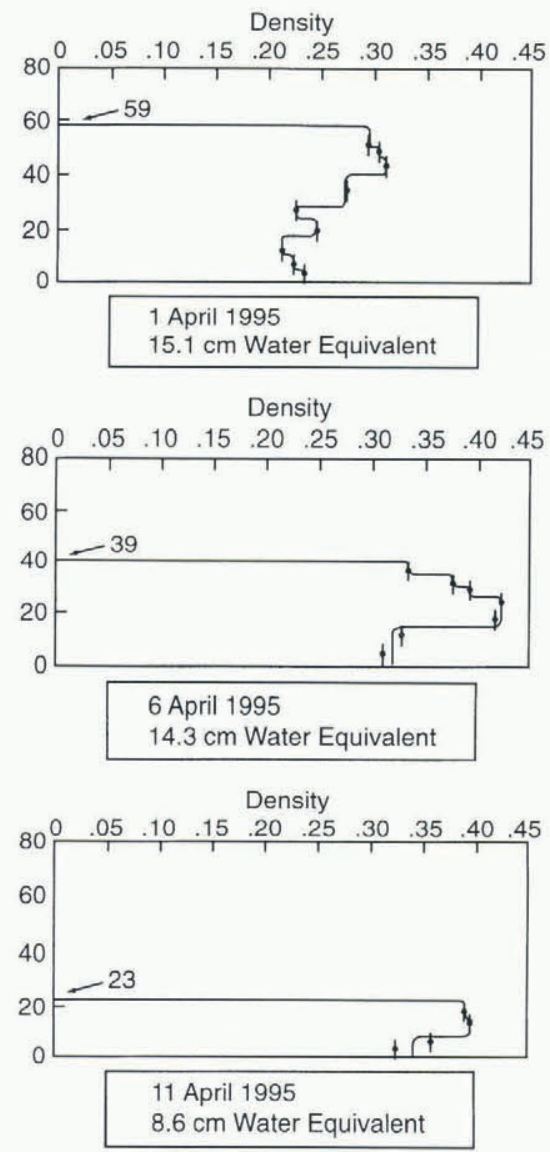

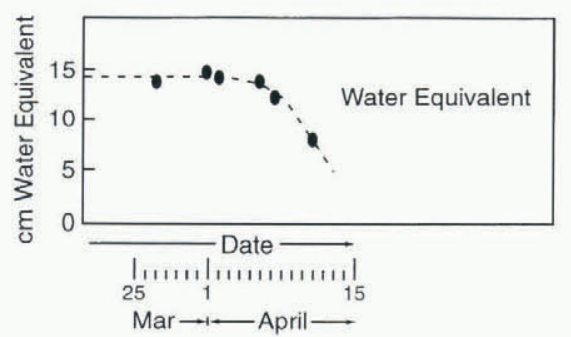

Fig. 1. Melting of the 1994-95 snowpack in interior Alaska. The snowpack of interior Alaska, which formed in October 1994, was at its maximum on 27 March 1995. Melt was underway by 1 April; density increased in the upper layers, but not at the bottom, as shown in the profiles from 1 and 2 April. By 6 April the bottom showed increased density but there was still no loss of mass from the snowpack. Loss of mass was rapid after 6 April. 
Although data were acquired at different solar zenith angles on different days, research has shown that, under clear skies, reflectance of snow does not vary much by solar zenith angle except at the extreme solar zenith angles (Cutler and Munro, 1996). Within a 4-6hour window centered on solar noon, satellite imagery is likely to be a reliable source of reflectivity estimates for snow and ice as these measured reflectances are within $2-3 \%$ of daily mean values (Cutler and Munro, 1996). Reflectance of vegetation does vary more with solar zenith angle at least in part because of temporal differences in the proportions of sunlit and shaded canopy (Vanderbilt and others, 1991). Thus, the solar zenith angle differences between flight lines are more significant for the vegetated areas than for the areas with no or low vegetation.

Reflectance will also vary with incidence angle in snowcovered forested areas. Reflectance decreases at incidence angles $>\approx 30^{\circ}$, and the snow-mapping algorithm will map less snow at higher incidence angles than it does at the nearnadir angles especially in densely forested areas. This is because, as the incidence angle becomes more oblique, more tree branches, stems and leaves fill the field of view of the sensor causing more vegetation and less snow to be observed. This causes the reflectance to decrease and less snow to be mapped. However, the effect of changing incidence angle is not considered in this paper.

Snow was mapped in various MAS images on different dates in April 1995. Areas that were mapped included: tundra on the Arctic Slope of Alaska, and a forested area near the Teklanika River, southwest of Fairbanks. In addition, reflectances in all the visible and near-infrared bands are plotted for Harding Lake, muskeg near the Chatanika River and forest near the Teklanika River.

\section{RESULTS AND DISCUSSION}

\section{Reflectance curves}

Reflectance curves (Fig. 2a, b and c) were constructed using MAS data in each of three surface covers. The shape of the curves varied among surface-cover types. Over snow- and ice-covered Harding Lake $\left(65.5^{\circ} \mathrm{N}, 147^{\circ} \mathrm{W}\right)$, nadir-viewing reflectances in the visible and near-infrared parts of the spectrum are very similar on 5 and $6 \mathrm{April}$ as would be expected (Fig. 2a). This is the case even though the solar zenith angles are approximately $60^{\circ}$ and $68.5^{\circ}$, respectively, at the time that the data were acquired. By 13 April (with a solar zenith angle of $56.1 \%$, with increased melting of the snow on top of the ice, and a resulting decrease in surface reflectance as more bare ice is present, reflectances in the visible and near-infrared parts of the spectrum are lower, although the shape of the curve is similar to that of the curves obtained on 5 and 6 April. Reflectances in the shortwave infrared part of the spectrum are very low and similar to those of the previous days. Inspection of Figure 1 shows a dramatic loss of snow depth and water equivalent between 6 and 11 April at the measurement site in Fairbanks. There was a similar situation on Harding Lake which explains the drop in reflectance, observed in Figure 2a, between 6 and 13 April. At the Fairbanks measurement site, by 13 April only patchy snow remained.

By 21 April, reflectances are lower in the visible and near-infrared parts of the spectrum and higher in the shortwave infrared parts of the spectrum than on the previous
LAKE
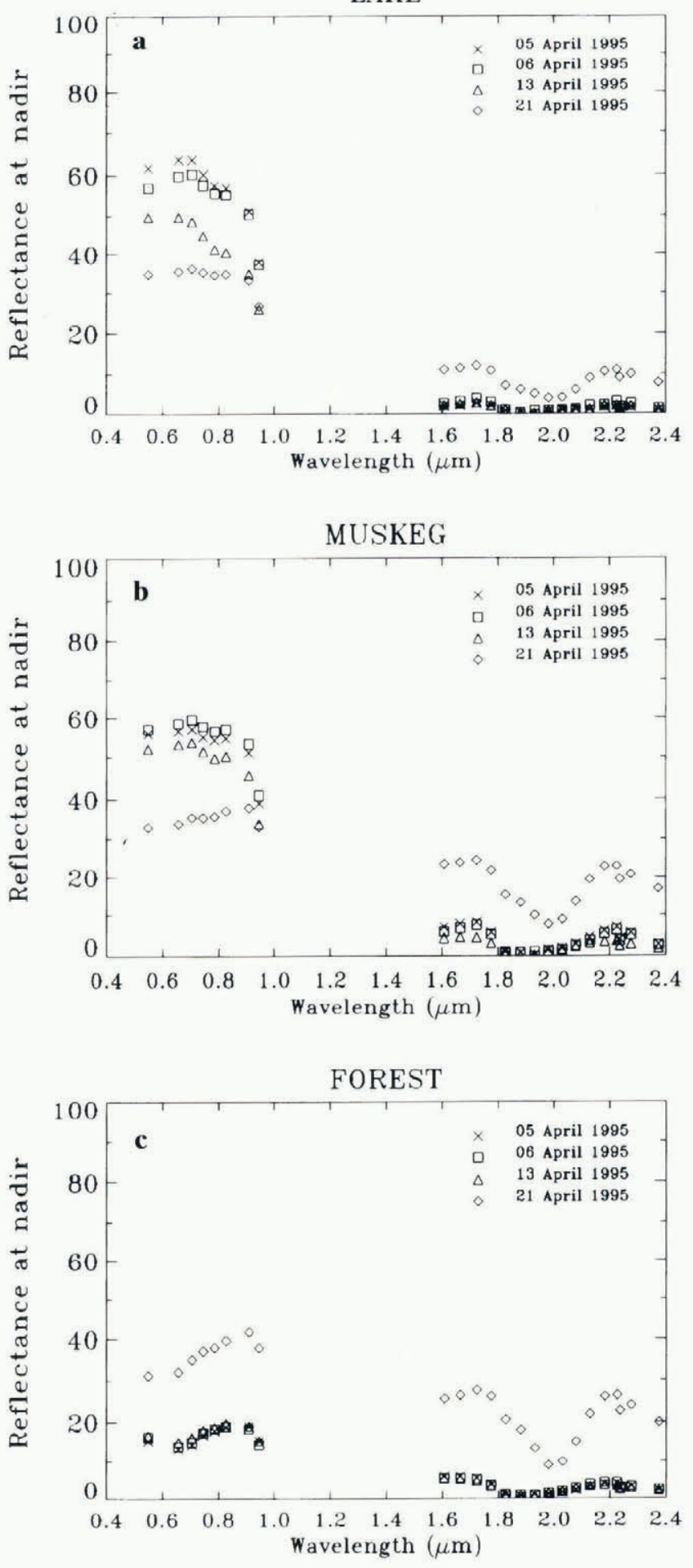

Fig. 2. Reflectance curves derived from MODIS Airborne Simulator (MAS) data from various dates in April 1995 from ER-2 overflights of central Alaska over different land covers.

flight days (Fig. 2a, b and c). In addition, the shape of the curve in the visible and near-infrared part of the spectrum is quite flat as compared to the curves derived from the data acquired on the previous flight days. This is not likely to be due to changes in the snow/ice conditions but more likely due to cirrus clouds that were observed to be over the Fairbanks grid during much of the ER-2 overflight on 21 April. The reflectance of clouds is greater than the reflectance of snow in the shortwave infrared part of the spectrum.

The reflectance curves of an area of muskeg $\left(65^{\circ} \mathrm{N}\right.$, $149^{\circ} \mathrm{W}$ ) are shown in Figure 2b. Because the muskeg of this 


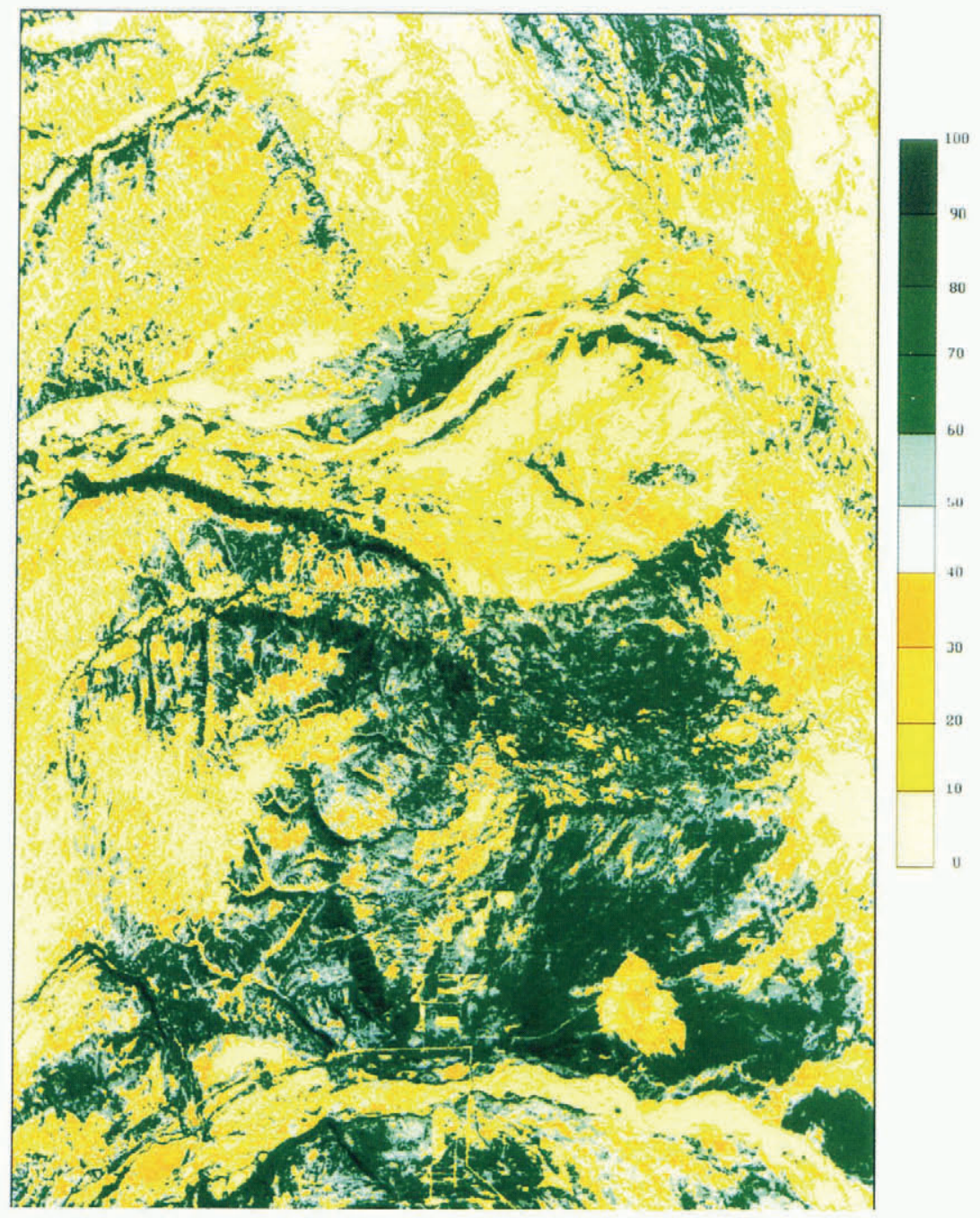

Fig. 3. Vegetation-cover density map of the 13 April 1995 . MAS scene over central Alaska, from MAS-derived reflectance data. Vegetation-cover density is given from 0 to $100 \%$ in increments of $10 \%$ as shown in the various colors.

area is composed of low vegetation, the reflectance of the snow-covered muskeg is quite high - almost as high as that of Harding Lake on 5 and 6 April. However, the shape of the curve is flat compared to the data acquired over Harding Lake because vegetation is present in addition to snow, changing the shape of the spectral reflectance curve. Reflectances in the mixed stands and spruce forest stands near the Teklanika River are low (generally $<20 \%$ in the visible and and near-infrared parts of the spectrum, and very low (generally $<5 \%$ ) in the shortwave infrared (Fig. 2). In the 1.6$1.8 \mu \mathrm{m}$ spectral region, vegetation has a higher reflectance than does snow. The low reflectances of the forest near the Teklanika River and the shape of the reflectance curves indicate that there is very little or no snow being sensed by the MAS in this area.

\section{Vegetation and snow mapping}

A vegetation-cover density map, based on $R_{\mathrm{i}}$ values, was constructed from 13 April 1995 MAS data (Fig. 3). Ten categories of vegetation density were established and each was assigned a color. When this map is overlain on part of the classified 9 September 1994 TM image, the areas mapped as $\geq 50 \%$ vegetation-cover density correspond to areas on the TM image which are classified as either coniferous or de- ciduous forests. Overall, the snow-mapping algorithm mapped $96.41 \%$ snow when the vegetation-cover density was $<50 \%$. Generally, the areas mapped as having $<50 \%$ vegetation-cover density correspond to areas classified on the TM image as muskeg. In areas of vegetation-cover density $\geq 50 \%, 71.23 \%$ snow was mapped with the algorithm.

On other dates in April, snow in tundra and muskeg areas was also mapped using MAS data. Results showed that nearly $100 \%$ snow cover was mapped in these areas using the MODIS snow-mapping algorithm.

Figure 4 shows a part of the 13 April 1995 channel 1 MAS scene (top), a binary version of the vegetation-cover density map of the same area (middle) and a snow map of the same area (bottom). These scenes were digitally overlaid. One can see the correspondence between snow mapped and less-dense $(<50 \%$ vegetation-cover density) vegetation between the middle and bottom images.

Overall, the MODIS snow-mapping algorithm mapped the 13 April 1995 MAS scene as being $87.41 \%$ snow-covered. However, the accuracy of this algorithm in central Alaska is actually $>87.41 \%$ because some of the area containing dense vegetation that is not mapped as snow cover is really not snow, and should not be classified as snow, because the area is covered by tree branches, stems and canopies. Even though the ground is continuously snow-covered, a snow- 

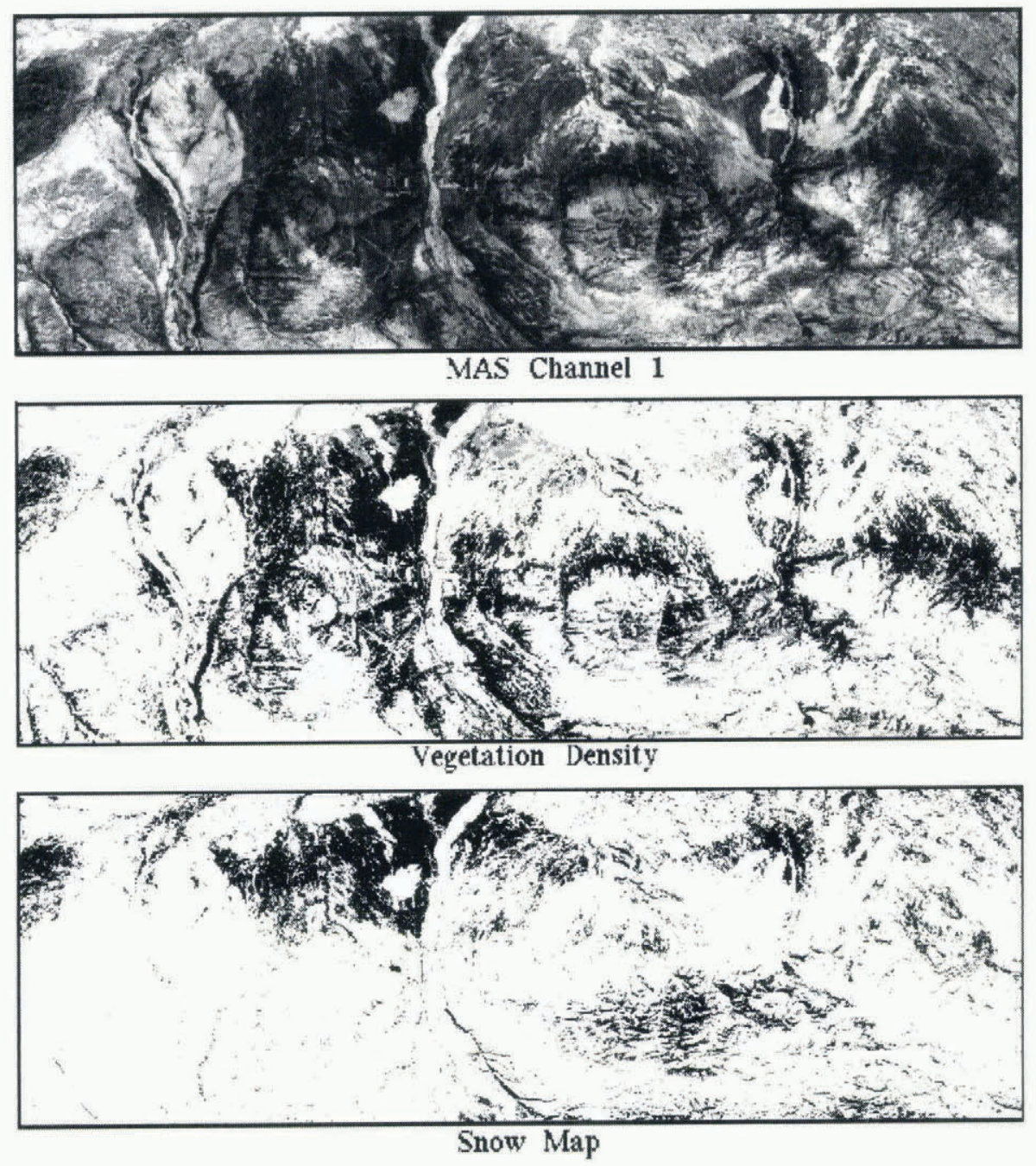

\section{April 1995}

Fig. 4. Channel 1 image of part of the 13 April 1995 MAS scene (top), vegetation-density map of the same image (either $<50 \%$ (white) or $\geq 50 \%$ (black) vegetation-cover density) (middle), and snow-cover map of the same image where snow cover is white and non-snow-covered areas are black (bottom).

mapping algorithm may not map $100 \%$ snow cover in a forested area. In addition, if there is snow in and on the forest canopy, this further confuses the issue.

\section{GONGLUSIONS}

Results of this study show that one can obtain an estimate of the vegetation-cover density in central Alaska based on the integrated reflectance, $R_{\mathrm{i}}$, values calculated from visible and near-infrared MAS data during April 1995 when continuous snow cover was present. This is because the reflectance in the visible and near-infrared part of the spectrum is, in general, inversely proportional to the density of vegetation when the ground is snow covered. This method of calculating vegetation density is used in lieu of a quantitative map of vegetation density which would be preferred but is not available at present.

The pixels from the 13 April MAS scene having the lowest $R_{\mathrm{i}}$ values correspond to the densest forests, both coniferous and deciduous, while the pixels having the highest $R_{\mathrm{i}}$ values correspond to areas that are devoid of vegetation. Pixels of intermediate $R_{\mathrm{i}}$ are composed of muskeg and mixed forests.

Using this information, we show that the MODIS snowhttps://doi.org/10.3189/1998AoG26-1-149-155 Published online by Cambridge University Press mapping algorithm is capable of detecting and mapping snow cover in central Alaska when the vegetation-cover density is less than about $50 \%$ with an accuracy of $96.41 \%$. When the vegetation-cover density is $\geq 50 \%$, the accuracy of snow mapping is $71.23 \%$. The accuracy of the snow-mapping algorithm varies with vegetation type and density in the areas studied and is better than $87.41 \%$ for a 13 April 1995 MAS scene containing a wide variety of land covers and vegetation-cover densities.

\section{AGKNOWLEDGEMENTS}

We would like to thank P. Masuoka of NASA/Goddard Space Flight Center for digitizing the vegetation map of Alaska prepared by Kuchler (1985), and D. Verbyla of the Department of Forest Service of the University of Alaska for discussions relating to the classification of the Landsat TM summer scene, and A. Klein of the Universities Space Research Association for his review of the paper. We would also like to thank P. Hubanks of General Services Corporation, Laurel, MD, for processing the MODIS Airborne Simulator (MAS) data. M. King of NASA/GSFC provided some support for the MAS mission in Alaska and for acquiring and processing the MAS data. This project was sup- 
ported by the Earth Observing System/Moderate Resolution Imaging Spectroradiometer (MODIS) snow and ice project.

\section{REFERENCES}

Chang, A. T. C., J. L. Foster and D. K. Hall. 1987. Nimbus-7 SMMR derived global snow cover parameters. Ann. Glaciol., 9, 39-44.

Cutler, P. M. and D. S. Munro. 1996. Visible and near-infrared reflectivity during the ablation period on Peyto Glacier, Alberta, Canada. F. Glaciol., 42 (141), 333-340.

Foster, J. L., A. T. C. Chang and D. K. Hall. 1994. Snow mass in boreal forests derived from a modified microwave algorithm. In Mougin, E., K. J. Ranson and J. A. Smith, eds. Multispectral and microwave sensing of foresty, hydrology, and natural resources. Bellingham, WA, Society of Photo-optical Instrumentation Engineers, 605-617.

Foster, J. L., D. K. Hall, A. T. C. Chang, A. Rango, W. Wergin and E. Erbe. 1996. Observations of snow crystal shape in cold snowpacks using scanning electron microscopy. In IGARSS'96. Remote Sensing for a Sustainable Future, 27-31 May 1996, Lincoln, Nebraska. Proceedings. Vol. 4. Pisacataway, NJ, Institute of Electrical and Electronic Engineers, 2011-2013.

Franklin, J. 1986. Thematic mapper analysis of coniferous structure and composition. Int. 7. Remote Sensing, 7, 1287-1301.

Hall, D. K., A. T. C. Chang, J. L. Foster, C. S. Benson and W. M. Kovalick. 1989. Comparison of in situ and Landsat derived reflectance of Alaskan glaciers. Remote Sensing Environ., 28, 23-31.

Hall, D. K., G. A. Riggs and V.V. Salomonson. 1995. Development of methods for mapping global snow cover using Moderate Resolution Imaging
Sepctroradiometer (MODIS) data. Remote Sensing Environ., 54 (2), 127-140. King, M. D., W. P. Menzel and 10 others. 1996. Airborne scanning spectrometer for remote sensing of cloud, aerosol, water vapor, and surface properties. 7. Atmos. Oceanic Technol., 13(4), 777-794.

Klein, A. G., D. K. Hall and G. A. Riggs. 1997. Improving the MODIS global snow-mapping algorithm. In IGARSS' 97. 17th International Geoscience and Remote Sensing Symposium, 3-8 August 1997, Singapore. Proceedings. Pisacataway, NJ, Institute of Electrical and Electronics Engineers, 619-621.

Knap, W. H. and J. Oerlemans. 1996. The surface albedo of the Greenland ice sheet: satellite-derived and in situ measurements in the Sondre Strømfjord area during the 1991 melt season. J. Glaciol., 42 (141), 364-374.

Kondrat'ev, K. Ya., ed. 1973. Radiation characteristics of the atmosphere and the Earth's surface. Washington, DC, National Aeronautics and Space Administration.

Kuchler, A. W. 1985. Potential natural vegetation. Washington, DC, U.S. Geological Survey, map. (National Atlas.)

Nolin, A.W. and J. Stroeve. 1997. The changing albedo of the Greenland ice sheet: implications for climate modeling. Ann. Glaciol., 25, 51-57.

Robinson, D. A. and G. Kukla. 1985. Maximum surface albedo of seasonally snow-covered lands in the Northern Hemisphere, 7. Climate Appl. Meteorol., 24(5), 402-411.

Townshend, J. R. G., C. J. Tucker and S. N. Goward. 1993. Global vegetation mapping. In Gurney, R. J., J. L. Foster and C. L. Parkinson, eds. Atlas of satellite observations related to global change. Cambridge, Cambridge University Press, $301-311$.

Vanderbilt, V. C. and 9 others. 1991. Biophysical information in asymmetric and symmetric diurnal bidirectional canopy reflectance. IEEE Trans. Geosci. Remote Sensing, GE-29(6), 875-888. 